\title{
Screening Recommendation Adherence Among First-Degree Relatives of People With Colorectal Cancer
}

Mark A Fiala ( $\square$ mfiala@dom.wustl.edu )

Washington University School of Medicine https://orcid.org/0000-0002-0208-5023

\section{Research Article}

Keywords: colorectal cancer screening, colonoscopy, first-degree relative, family history

Posted Date: September 28th, 2021

DOl: https://doi.org/10.21203/rs.3.rs-841341/v1

License: (c) (i) This work is licensed under a Creative Commons Attribution 4.0 International License.

Read Full License 


\section{Abstract}

Purpose: To determine what factors are associated with colorectal cancer (CRC) screening adherence among first-degree relatives (FDRs) of people with CRC.

Methods: The study used data from the 2015 National Health Interview Survey, a nationally representative survey in the US. Self-reported CRC screening rates were compared between FDRs and their peers without a family history of CRC. Participants were considered to be adherent if they had undergone any of the following: fecal immonchemical test within the prior 1 year, sigmoidscopy or computed tomography colongraphy within 5 years, or colonoscopy within 10 years. Multivariable models of CRC screening adherence were created for both cohorts and the results compared.

Results: The analysis included 11,381 people age $50-75$ at time of survey. Overall, $62 \%$ of participants were adherent to screening recommendations. FDR of people with CRC were more likely to be adherent ( $76 \%$ compared to $61 \%, p<0.001$ ). In the multivariable models, a FDR with CRC was associated with an $86 \%$ increase in odds of being adherent to recommendations (aOR 1.86; 95\% Cl 1.59-2.59). Race, ethnicity, and socioeconomic variables were all associated with adherence. Models were largely similar between FDRs of people with CRC and the general public.

Conclusions: Approximately one-quarter of FDRs of people with CRC are not adherent to screening recommendations. Further outreach is needed for members of minority races and the Hispanic community and additional efforts are needed to increase the accessibility of CRC screening for those with more limited finances and the uninsured.

\section{Introduction}

A history of colorectal cancer (CRC) among a first-degree relative (FDR), mother, father or sibling, is one of the most important risk factors for the disease. The risk is estimated to be two- to four-fold that of the peers without a family history of CRC [1]. Although colorectal cancer screening is recommended for all people aged 50-75, it is of even greater importance for high-risk individuals, including to those with a family history of CRC [2]. Some professional organizations recommend those with higher risk be screened starting at a younger age and at more frequent intervals [3].

There are several modalities for CRC screening including: computed tomography colongraphy (CTC), also referred to as a "virtual colonoscopy"; fecal immonchemical test (FIT); sigmoidoscopy; and colonoscopy. In the average risk population, CTC, FIT, or sigmoidoscopy may provide similar benefits in reduction of CRC-related mortality as colonoscopy [4]. Among higher-risk individuals, colonoscopy is still the standard because it not only can lead to earlier detection of CRC; removal of precancerous lesions during the procedure can prevent CRC.

Perhaps counterintuitively, the detection of precancerous lesions, often referred to as polyps, during colonoscopy is associated with superior clinical outcomes in terms of reducing CRC risk [5]. However, 
polyp detection seems to be associated with a more thorough procedure, a more meticulous inspection and/or for longer duration, and not necessarily related to the disease process [6]. The detection of at least one polyp is a widely used quality indicator [7].

Despite the evidence supporting the benefit of colonoscopy among FDRs of those with CRC, rates in the United States have historically been low; a meta-analysis estimated that only $40 \%$ (95\% Cl $26 \%-54 \%$ ) of eligible, those age 50-75, underwent colonoscopy [8]. However, the studies included in the analysis ranged from 1999-2009 and may not reflect current trends. A study using data from the 2009 California Health Interview Survey found that $73 \%$ of those with a FDR with CRC reported having a screening colonoscopy [9].

FDRs of people with CRC can encounter a myriad of barriers to screening [10]. They may not even be aware that their status is associated with a higher risk of CRC or that screening colonoscopy may help mitigate that excess risk. Some may abstain due to a fear of being diagnosed with CRC or due to negative attitudes regarding colonoscopy, disputing its effectiveness, or out of consideration on the associated discomfort and complications.

CRC screening, particularly colonoscopy, can also be costly and those without insurance may have more limited access. One study found only $44 \%$ of uninsured individuals age $50-64$ reported undergoing colonoscopy compared to $57 \%$ of those with insurance [11]. Another, found that people reporting difficultly affording healthcare were less than half as likely (aOR $0.41 ; 95 \% \mathrm{Cl} 0.22-0.74$ ) to have had a colonoscopy or sigmoidoscopy [12].

Following approval of the Affordable Care Act in the United States in 2011, CRC screening including colonoscopy is required to be covered by insurance providers without cost sharing, co-pays, coinsurance, and deductibles. However, if performed for surveillance or diagnostic purposes or when a polyp is detected and removed during screening, the procedure may be subject to cost sharing [13].

Other cultural and demographics factors have been associated with CRC screening adherence. Black Americans, who have the highest incidence of and mortality from CRC, have had lower rates of CRC screening than their Caucasian peers [14-15]. Even lower rates of CRC screening have been observed among those of Asian or Hispanic heritage [15]. However, these observations were among the general population and it is unclear if similar trends persist among those who have FDR with CRC. In this study, we sought to determine what factors are associated with CRC screening recommendation adherence among FDRs of patients with CRC.

\section{Methods}

\section{Data Source}

Data from the 2015 National Heath Information Survey (NHIS) Cancer Control Supplement (CCS) was used to compare the self-reported adherence with colorectal screening recommendation guidelines of 
FDRs of people with CRC and their peers without a family history of CRC. The NHIS is a cross-sectional, nationally representative, household survey of non-military and non-institutionalized individuals living in the United States. [16] The Census Bureau administers the NHIS survey annually, throughout each year, using computer-assisted personal interviewing. The core questionnaire remains consistent each year and includes demographic characteristics, health insurance, health care access and use, health conditions, tobacco use, and functioning and disability. Additional questionnaires are rotated each year, some with fixed periodicity, some ad hoc. The data are openly available from the Centers for Disease Control and Prevention at http://www.cdc.gov/nchs/nhis.htm [16].

The CCS is an additional module that is administered to adult participants of the NHIS covering diet and nutrition, physical activity, cancer screening, genetic testing, and family history of cancer. It is cosponsored by the National Cancer Institute and the Centers for Disease Control and Prevention. It was first administered in 1987 and subsequently has been administered approximately every 5 years through 2015. Since 2019, the CCS has been integrated into the annual NHIS adult survey with questions rotating each year. The 2015 NHIS CCS was used for this analysis. Although the 2019 NHIS CCS data is available at time of analysis, the survey did not include family history of cancer, which precluded its use.

\section{Participants}

In 2015 , the NHIS surveyed 33,672 adults. The analysis was limited to the 13,707 who were $50-75$, inclusive, at time of survey, consistent with the recommendations for CRC screening at the time. Although some professional organizations recommend earlier screening for higher-risk individuals, [3] the practice is still not universal. Further, 119 participants who reported a personal history of colorectal cancer, and 2,207 where familial history of colorectal was unknown, were excluded leaving a final analysis cohort of 11,381 .

\section{Measures}

Demographic data, age, sex, race, ethnicity, geographical region of the country, education, marital status, family income relative to poverty threshold, and insurance coverage were extracted from the files. To approximate each participant's affordability of healthcare, a composite variable was created using a series of questions regarding affordability of healthcare including: prescription medicines, mental health care/counseling, dental care, to see a specialist, and follow-up care. The questions are formatted as the following example:

"During the past 12 months, was there any time when you needed any of the following, but didn't get it because you couldn't afford it? ... Prescription medicines."

A positive response to any was coded as the participant reporting issues with the affordability of healthcare.

CRC screening was based on self-report. Participants were considered to be adherent to CRC screening guidelines if they had undergone any of the following: FIT within the prior 1 year, sigmoidscopy or CTC within 5 years, or colonoscopy within 10 years. 


\section{Statistical Analysis}

The composition of the study cohort and the frequency of CRC screening tests were reported descriptively. The characteristics of the participants with FDR's with CRC were compared to those who did not using bivariate statistics. Multivariable models of colonoscopy recommendation adherence were created for: 1) the entire cohort; 2) for FDR of people with CRC; 3) for those without a family history of CRC. Subsequently, the model results between FDR and their peers without a family history of CRC were compared using interaction variables between each predictor variable and family history of CRC to determine if the relationship between the predictor and colonoscopy adherence was moderated by a family history of CRC.

\section{Results}

Of the 11,381 participants included in the analysis, $9 \%(n=1,074)$ reported a history of CRC among a FDR. Participant characteristics segmented by FDR status is summarized in Table 1. Those who were are FDR of a person with CRC were slightly older on average, more likely to be black, non-Hispanic, reside in the southern region of the United States, have a prior cancer (non-colorectal) diagnosis themselves, and to be insured by Medicare. There was no difference in between the two groups in relation to poverty status, being uninsured, or self-reported difficulty affording healthcare. 
Table 1

Study Demographics

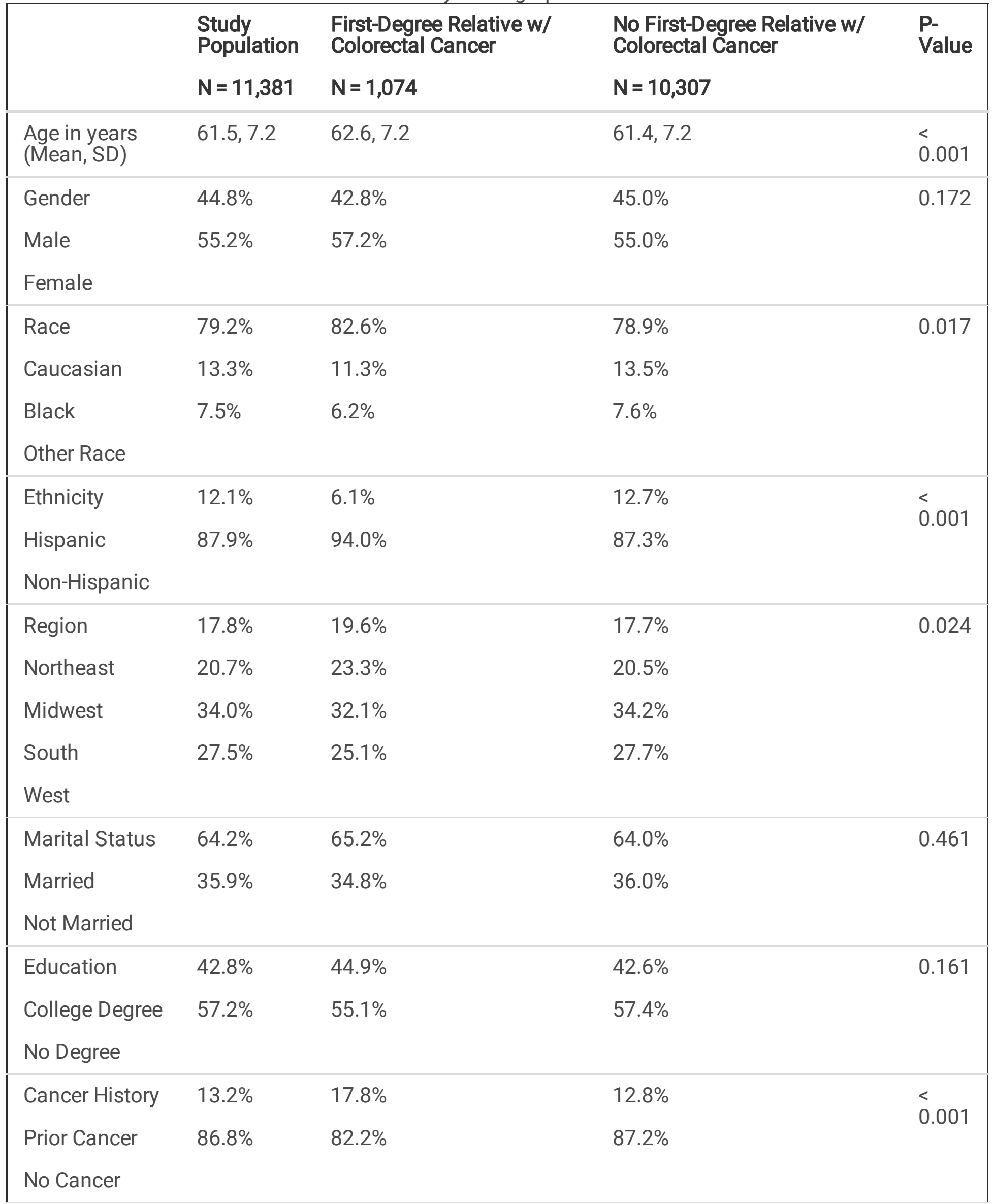




\begin{tabular}{|c|c|c|c|c|}
\hline & $\begin{array}{l}\text { Study } \\
\text { Population } \\
N=11,381\end{array}$ & $\begin{array}{l}\text { First-Degree Relative w/ } \\
\text { Colorectal Cancer } \\
\mathrm{N}=1,074\end{array}$ & $\begin{array}{l}\text { No First-Degree Relative w/ } \\
\text { Colorectal Cancer } \\
N=10,307\end{array}$ & $\begin{array}{l}\text { P- } \\
\text { Value }\end{array}$ \\
\hline Family Income & $12.3 \%$ & $10.7 \%$ & $12.5 \%$ & 0.111 \\
\hline $\begin{array}{l}\text { Below Poverty } \\
\text { Above Poverty }\end{array}$ & $87.7 \%$ & $89.3 \%$ & $87.5 \%$ & \\
\hline $\begin{array}{l}\text { Insurance } \\
\text { Provider } \\
\text { Uninsured } \\
\text { Private } \\
\text { Medicaid } \\
\text { Medicare }\end{array}$ & $\begin{array}{l}6.5 \% \\
45.1 \% \\
6.7 \% \\
41.7 \%\end{array}$ & $\begin{array}{l}5.4 \% \\
41.2 \% \\
4.9 \% \\
48.6 \%\end{array}$ & $\begin{array}{l}6.6 \% \\
45.5 \% \\
6.9 \% \\
41.0 \%\end{array}$ & $\begin{array}{l}< \\
0.001\end{array}$ \\
\hline $\begin{array}{l}\text { Healthcare } \\
\text { Affordability } \\
\text { Reported } \\
\text { Issues } \\
\text { No Issues }\end{array}$ & $\begin{array}{l}18.0 \% \\
82.0 \%\end{array}$ & $\begin{array}{l}19.1 \% \\
80.9 \%\end{array}$ & $\begin{array}{l}17.9 \% \\
82.1 \%\end{array}$ & 0.344 \\
\hline
\end{tabular}

The majority of participants (63\%) reported having a discussion with a doctor regarding CRC screening. It was even more common among FDRs of people with CRC than their peers $(75 \%$ compared to $62 \%$; $p<$ 0.001). The frequency of CRC screening modalities are summarized in Table 2. Colonoscopy was by far the most utilized. Fifty-eight percent of participants reported undergoing colonoscopy within the prior 10 years and, of those whom were adherent to screening recommendations, $94 \%$ had undergone colonoscopy. 
Table 2

Colorectal Cancer Screening

\begin{tabular}{|lllll|}
\hline & $\begin{array}{l}\text { Study } \\
\text { Population } \\
\mathbf{N = 1 1 , 3 8 1}\end{array}$ & $\begin{array}{l}\text { First-Degree } \\
\text { Relative w/ } \\
\text { Colorectal Cancer } \\
\mathbf{N = 1 , 0 7 4}\end{array}$ & $\begin{array}{l}\text { No First-Degree } \\
\text { Relative w/ } \\
\text { Colorectal Cancer } \\
\mathbf{N}=10,307\end{array}$ & $\begin{array}{c}\text { P- } \\
\text { Value }\end{array}$ \\
\hline $\begin{array}{l}\text { Colonoscopy in the prior 10 } \\
\text { years }\end{array}$ & $58.4 \%$ & $74.7 \%$ & $56.6 \%$ & 0.001 \\
\hline $\begin{array}{l}\text { Fecal Immonchemical Test } \\
\text { (FIT) in the prior 1 year }\end{array}$ & $9.4 \%$ & $7.8 \%$ & $9.6 \%$ & 0.058 \\
\hline $\begin{array}{l}\text { Sigmoidoscopy in the prior 5 } \\
\text { years }\end{array}$ & $1.9 \%$ & $2.0 \%$ & $1.9 \%$ & 0.849 \\
\hline $\begin{array}{l}\text { Computed Tomography } \\
\text { Colongraphy (CTC) in the prior }\end{array}$ & $0.7 \%$ & $1.1 \%$ & $0.6 \%$ & 0.071 \\
\hline years & & $76.2 \%$ & $61.0 \%$ & $<.001$ \\
\hline Any of the above & $62.4 \%$ & & & \\
\hline
\end{tabular}

Of those who underwent colonoscopy, $36 \%$ reported a doctor notifying them of precancerous lesions found. This was more common among FDRs of people with CRC than their peers (49\% compared to $35 \%$, $p<0.001)$. The majority of participants had the colonoscopy covered by insurance, $67 \%$ reported no cost sharing related to the procedure, while $30 \%$ reported paying some, and $4 \%$ reported paying all of the cost. FIT was the second most common modality of CRC screening with $8 \%$ of participants undergoing the test in the prior year. Sigmoidscopy and CTC were not common; less than $2 \%$ and $1 \%$ of participants underwent the procedures in the prior 5 years, respectively.

Overall, $62 \%$ of participants were adherent to CRC screening recommendations. FDR of people with CRC were more likely to be adherent than their peers $(76 \%$ compared to $61 \%, p<0.001)$. which can be attributed to higher colonoscopy utilization $(75 \%$ compared to $56 \% ; p<0.001)$. FIT, sigmoidoscopy, and computerized tomography rates were similar between the groups.

Multivariable models of CRC screening adherence are summarized in Table 3. Having a FDR with CRC was associated with an $86 \%$ increase in odds of being adherent to recommendations (aOR $1.86 ; 95 \% \mathrm{Cl}$ 1.59-2.59). Black Americans were more likely to be adherent than Caucasian Americans ( $\mathrm{aOR}=1.15$; $95 \% \mathrm{Cl} 1.01-1.31$ ) while those who identified as a race other than Caucasian or Black were less likely to be adherent (aOR $0.72 ; 95 \% \mathrm{Cl} 0.61-0.85$ ) as were Hispanic people compared to non-Hispanics (aOR $0.74 ; 95 \% \mathrm{Cl} 0.65-0.85)$. Increased odds of being adherence to CRC recommendations were also observed for those with advancing age, with a personal medical history of cancer, residing in the Northeast region of the United States, those married, and those with a college education. Decreased odds were observed for those living in poverty and those who were uninsured or enrolled in Medicaid. 
Table 3

Multivariable Models of Colonoscopy Recommendation Adherence

\begin{tabular}{|c|c|c|c|c|c|c|c|}
\hline & \multicolumn{2}{|c|}{$\begin{array}{l}\text { Model } 1 \\
\text { All Participants } \\
\mathrm{N}=11,381\end{array}$} & \multicolumn{2}{|c|}{$\begin{array}{l}\text { Model } 2 \\
\text { First-Degree Relative } \\
\text { w/ Colorectal Cancer } \\
N=1,074\end{array}$} & \multicolumn{2}{|c|}{$\begin{array}{l}\text { Model } 3 \\
\text { No First-Degree } \\
\text { Relative w/ Colorectal } \\
\text { Cancer } \\
\mathrm{N}=10,307\end{array}$} & \multirow[t]{2}{*}{$\begin{array}{l}\text { P- } \\
\text { Value }\end{array}$} \\
\hline $\begin{array}{l}\text { First-Degree Relative } \\
\text { with Colorectal } \\
\text { Cancer }\end{array}$ & $\begin{array}{l}1.86 \\
(1.59- \\
2.18)\end{array}$ & $<.001$ & & & & & \\
\hline Age (per year) & $\begin{array}{l}1.05 \\
(1.04- \\
1.06)\end{array}$ & $<.001$ & $\begin{array}{l}1.07(1.04- \\
1.11)\end{array}$ & $<.001$ & $\begin{array}{l}1.05(1.04- \\
1.06)\end{array}$ & $<.001$ & 0.181 \\
\hline Female Gender & $\begin{array}{l}1.07 \\
(0.98- \\
1.16)\end{array}$ & 0.150 & $\begin{array}{l}1.60(1.16- \\
2.19)\end{array}$ & 0.004 & $\begin{array}{l}1.03(0.94- \\
1.13)\end{array}$ & 0.502 & 0.009 \\
\hline Black Race & $\begin{array}{l}1.15 \\
(1.01- \\
1.31)\end{array}$ & .040 & $\begin{array}{l}0.80(0.49- \\
1.32)\end{array}$ & 0.388 & $\begin{array}{l}1.18(1.03- \\
1.35)\end{array}$ & 0.020 & 0.147 \\
\hline Other Race & $\begin{array}{l}0.72 \\
(0.61- \\
0.85)\end{array}$ & $<.001$ & $\begin{array}{l}0.90(0.48- \\
1.66)\end{array}$ & 0.727 & $\begin{array}{l}0.71(0.60- \\
0.84)\end{array}$ & $<.001$ & 0.474 \\
\hline Hispanic & $\begin{array}{l}0.74 \\
(0.65- \\
0.85)\end{array}$ & $<.001$ & $\begin{array}{l}0.71(0.40- \\
1.29)\end{array}$ & 0.261 & $\begin{array}{l}0.75(0.65- \\
0.86)\end{array}$ & $<.001$ & 0.882 \\
\hline Midwest Region & $\begin{array}{l}0.72 \\
(0.63- \\
0.83)\end{array}$ & $<.001$ & $\begin{array}{l}0.84(0.51- \\
1.39)\end{array}$ & 0.499 & $\begin{array}{l}0.71(0.62- \\
0.82)\end{array}$ & $<.001$ & 0.531 \\
\hline Southern Region & $\begin{array}{l}0.69 \\
(0.60- \\
0.78)\end{array}$ & $<.001$ & $\begin{array}{l}0.89(0.55- \\
1.44)\end{array}$ & 0.628 & $\begin{array}{l}0.68(0.59- \\
0.77)\end{array}$ & $<.001$ & 0.286 \\
\hline Western Region & $\begin{array}{l}0.74 \\
(0.65- \\
0.85)\end{array}$ & $<.001$ & $\begin{array}{l}0.82(0.51- \\
1.33)\end{array}$ & 0.428 & $\begin{array}{l}0.74(0.64- \\
0.85)\end{array}$ & $<.001$ & 0.677 \\
\hline Married & $\begin{array}{l}1.30 \\
(1.18- \\
1.42)\end{array}$ & $<.001$ & $\begin{array}{l}1.06(0.75- \\
1.49)\end{array}$ & 0.735 & $\begin{array}{l}1.32(1.20- \\
1.45)\end{array}$ & $<.001$ & 0.232 \\
\hline College Degree & $\begin{array}{l}1.55 \\
(1.42- \\
1.70)\end{array}$ & $<.001$ & $\begin{array}{l}1.54(1.11- \\
2.14)\end{array}$ & 0.011 & $\begin{array}{l}1.56(1.42- \\
1.71)\end{array}$ & $<.001$ & 0.947 \\
\hline $\begin{array}{l}\text { Personal Cancer } \\
\text { History }\end{array}$ & $\begin{array}{l}1.75 \\
(1.53- \\
2.01)\end{array}$ & $<.001$ & $\begin{array}{l}2.20(1.34- \\
3.61)\end{array}$ & 0.002 & $\begin{array}{l}1.71(1.48- \\
1.98)\end{array}$ & $<.001$ & 0.344 \\
\hline
\end{tabular}




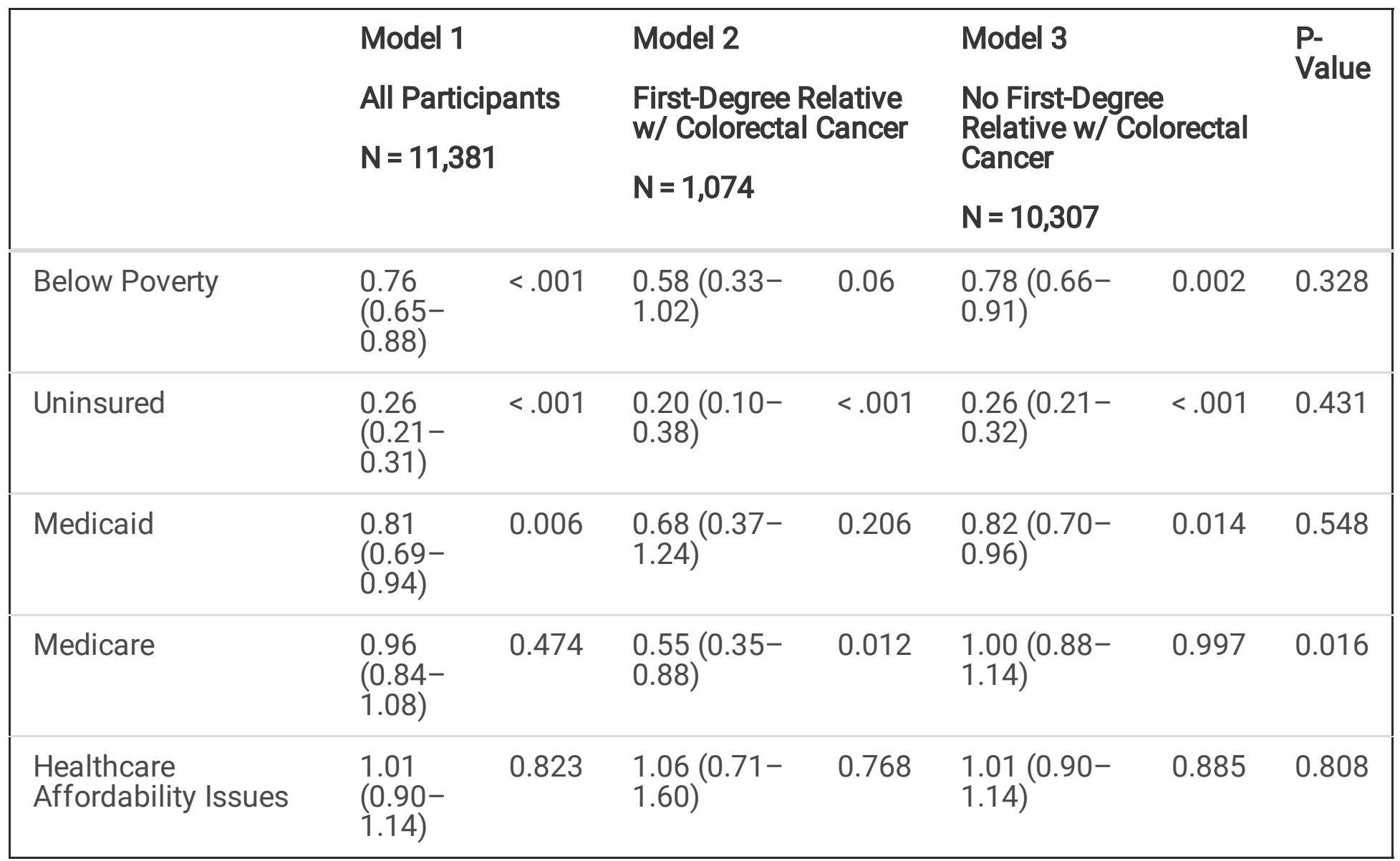

The results of the multivariable analysis were largely consistent across both -analyses, of FDRs and nonFDRs. Among FDRs of people with CRC, females were more likely to be adherent than males (aOR 1.60; 95\% $\mathrm{Cl} 1.16-2.19$ ) and enrollment in Medicare was associated with a decrease in odds of being adherent (aOR 0.55; 95\% $\mathrm{Cl} 0.35-0.87$ ). Among those without a FDR with CRC gender and Medicare enrollment were not associated with screening adherence. The difference in the model results were statistically significant $(p=0.009$ and $p=0.016$, respectively).

\section{Discussion}

This study found that the predictors of CRC screening adherence were largely similar between FDR of people with CRC and the general public. Moreover, FDR were more likely to have had a discussion with a doctor regarding $\mathrm{CRC}$ screening and be adherent to screening recommendations than the general public. This suggests that many members in the group understand the increased risk. However, it is still likely that many do not.

Efforts to improve CRC screening among FDRs of people with CRC should focus on tailored communications specific to the population and their increased risk for the disease. Tailored communications have been shown to be about twice as likely to result in colonoscopy compared to more general communications [17]. In addition, having the FDR with CRC advocating for screening to their relatives at increased risk is an effective way to reduce barriers related to fear of or apprehension to the procedure [18]. 
Promoting CRC screening may not benefit some of the population who would undergo the procedure but cannot due to cost issues. CRC screening is now provided largely without cost sharing for those insured [13]; however, one-third of participants in this study still reported paying some or all of the costs out-ofpocket. As this study found, being in poverty, uninsured, or covered by Medicaid were among the strongest associated variables with adherence. This is not limited to CRC screening, financial hardship has been associated with decreased likelihood of undergoing screening for breast and cervical cancer as well [19].

Among FDR of people with CRC, Medicare insurance was associated with reduced odds of colonoscopy compared to private insurance. This was not observed among the general population. The reason for these conflicting results are unclear. Medicare covers CRC screening at no-cost unless a polyp is detected, in that event, it is no longer considered screening and cost-sharing applies. About half of all participants in this study with a FDR with CRC reported polyps. It is possible that people are avoiding the procedure because of the anticipated out-of-pocket costs.

The concept of financial toxicity, the negative outcome that results from perceived 'subjective financial distress' and 'objective financial burden', has become widely accepted among people with cancer [20]. It puts patients with cancer at greater risk for medical non-adherence, the delaying, rationing, or foregoing of needed care in attempt to reduce costs [21]. I suggest that a similar phenomenon may be occurring here where people may be forgoing CRC screening because of the potential costs. Interestingly, the study did not observe an association between self-reported healthcare affordability issues and CRC screening. As the models also included health insurance coverage, Medicaid enrollment, and household income, all related to CRC screening and also likely to healthcare affordability, it is possible that these mediate the previously reported relationship [12].

Groups like the American Cancer Society advocate for eliminating cost-sharing associated with cancer screenings to improve adherence among those with more limited finances [22]. Sweeden implemented universal free mammography for females age 40-74 in 2016; previously the charge was approximately \$23 US dollars on average. This resulted in statistically significant increases in adherence among females with the lowest incomes and in areas with higher cost sharing [23].

Another finding of the current study is that while Black Americans were more likely to be adherent to CRC than their white peers. This finding is inconsistent with earlier reports [15]. Interestingly, in the current study, among people with a FDR with CRC there was a trend for reduced adherence among Black Americans compared to Caucasians, but it was not statistically significant. A prior study found that among Black Americans, a familial history of CRC did not increase adherence rates, but did for all other racial groups [24]. In a post-hoc analysis, the current study found that Black Americans with a family history of CRC were more likely to be adherent to screening recommendations ( $70 \%$ compared to $61 \% ; p=$ 0.040; data not shown).

Efforts to increase adherence in the Black and African American community in recent years seem to have been effective, possibly even more effective among those with a FDR with CRC. Additional efforts are 
needed among members of other racial groups and the Hispanic community who still have lower rates. In particular, patient navigators, a specifically trained person who helps a person obtain medical care, are beneficial for increasing screening rates but availability is still limited and some patients are hesitant to use the services [25].

The association of lower CRC screening adherence among males who are FDRs of a person with CRC is novel. A prior study using the 2005 California Health Interview Survey had very contrary findings. The researchers reported that females who had a familial history of CRC (first- or second-degree relatives) were $17 \%$ less likely to be adherent than their male counterparts [26]. Among those without a family history of CRC, neither the current study nor the former found an association between gender and CRC screening adherence among the general population. Other studies regarding in the general population have reported mixed results [27]. Additional research is needed to clarify the inconsistent results and determine the causes of any gender-based disparities.

The strength of the study is its large and nationally representative sample. However, it is not without its limitations. All measures were patient self-report and may not reflect actual screening behaviors or other measures. As with all observational studies, causality cannot be assumed for the associations found. Additionally, the data was collected in 2015 and may not be representative of current trends. While the NHIS is now collecting data for the CCS annually with each survey, the content is rotating and rather limited. It is unclear if/when the colorectal screening behavior and family history modules will be collected concurrently in future years. Lastly, the study was conducted in the United States, a country without universal healthcare coverage, and findings may not generalize to other countries.

Despite these limitations, this study adds to limited, although growing, body of literature regarding the screening behaviors of FDRs of people with CRC. The data suggests that although FDRs of people with CRC are more adherent to screening recommendations than their peers, about one-quarter still are not. Additional outreach is needed to members of the Hispanic community and those who identify as a race other than Caucasian or Black. If these measures are designed to target those with FDRs with CRC, tailored communications to members of that group will likely be more effective than more general communications regarding CRC screening. There is also a need to increase accessibility of CRC screening as living under the poverty level, being uninsured, or enrolled on Medicaid were among the strongest predictors of adherence.

\section{Declarations}

Funding: Not applicable

Conflicts of interest/Competing interests: The author has no relevant conflicts to disclose.

Ethics approval: Exempt as only non-identifiable data accessed

Consent to participate: Not applicable 
Consent for publication: Not applicable

Availability of data and material: Publically Available

Code availability: Upon request

Author Contributions: The author contributed to all aspects of the research, analysis, and manuscript preparation.

Acknowledgements: I would like to thank the National Heath Interview Survey staff and participants, and the National Center for Health Statistics (NCHS) which is part of the Centers for Disease Control and Prevention (CDC) for making the data publicly available.

\section{References}

1. Henrikson NB, Webber EM, Goddard KA, Scrol A, Piper M, Williams MS, Zallen DT, Calonge N, Ganiats TG, Janssens AC, Zauber A, Lansdorp-Vogelaar I, van Ballegooijen M, Whitlock EP (2015) Family history and the natural history of colorectal cancer: systematic review. Genetics in medicine: official journal of the American College of Medical Genetics 17(9):702-712.

https://doi.org/10.1038/gim.2014.188

2. US Preventive Services Task Force, Bibbins-Domingo K, Grossman DC, Curry SJ, Davidson KW, Epling JW Jr, García F, Gillman MW, Harper DM, Kemper AR, Krist AH, Kurth AE, Landefeld CS, Mangione CM, Owens DK, Phillips WR, Phipps MG, Pignone MP, Siu AL (2016) Screening for Colorectal Cancer: US Preventive Services Task Force Recommendation Statement. JAMA, 315(23), 2564-2575. https://doi.org/10.1001/jama.2016.5989

3. Levin B, Lieberman DA, McFarland B, Smith RA, Brooks D, Andrews KS, Dash C, Giardiello FM, Glick S, Levin TR, Pickhardt P, Rex DK, Thorson A, Winawer SJ, American Cancer Society Colorectal Cancer Advisory Group, US Multi-Society Task Force, \& American College of Radiology Colon Cancer Committee (2008) Screening and surveillance for the early detection of colorectal cancer and adenomatous polyps, 2008: a joint guideline from the American Cancer Society, the US Multi-Society Task Force on Colorectal Cancer, and the American College of Radiology. Cancer J Clin 58(3):130160. https://doi.org/10.3322/CA.2007.0018

4. Knudsen AB, Rutter CM, Peterse E, Lietz AP, Seguin CL, Meester R, Perdue LA, Lin JS, Siegel RL, DoriaRose VP, Feuer EJ, Zauber AG, Kuntz KM, Lansdorp-Vogelaar I (2021) Colorectal Cancer Screening: An Updated Modeling Study for the US Preventive Services Task Force. JAMA 325(19):1998-2011. https://doi.org/10.1001/jama.2021.5746

5. Corley DA, Jensen CD, Marks AR, Zhao WK, Lee JK, Doubeni CA, Zauber AG, de Boer J, Fireman BH, Schottinger JE, Quinn VP, Ghai NR, Levin TR, Quesenberry CP (2014) Adenoma detection rate and risk of colorectal cancer and death. N Engl J Med 370(14):1298-1306.

https://doi.org/10.1056/NEJMoa1309086

Page $13 / 15$ 
6. Rex DK, Schoenfeld PS, Cohen J, Pike IM, Adler DG, Fennerty MB, Lieb JG 2nd, Park WG, Rizk MK, Sawhney MS, Shaheen NJ, Wani S, Weinberg DS (2015) Quality indicators for colonoscopy. Gastrointest Endosc 81(1):31-53. https://doi.org/10.1016/j.gie.2014.07.058

7. Rex DK, Petrini JL, Baron TH, Chak A, Cohen J, Deal SE, Hoffman B, Jacobson BC, Mergener K, Petersen BT, Safdi MA, Faigel DO, Pike IM, \& ASGE/ACG Taskforce on Quality in Endoscopy (2006). Quality indicators for colonoscopy. The American journal of gastroenterology, 101(4), 873-885. https://doi.org/10.1111/j.1572-0241.2006.00673.x

8. Ait Ouakrim D, Lockett T, Boussioutas A, Hopper JL, Jenkins MA (2013) Screening participation for people at increased risk of colorectal cancer due to family history: a systematic review and metaanalysis. Familial cancer 12(3):459-472. https://doi.org/10.1007/s10689-013-9658-3

9. Perencevich M, Ojha RP, Steyerberg EW, Syngal S (2013) Racial and ethnic variations in the effects of family history of colorectal cancer on screening compliance. Gastroenterology 145(4):775-81.e2. https://doi.org/10.1053/j.gastro.2013.06.037

10. Tan KK, Lopez V, Wong ML, Koh GC (2018) Uncovering the barriers to undergoing screening among first degree relatives of colorectal cancer patients: a review of qualitative literature. Journal of gastrointestinal oncology 9(3):579-588. https://doi.org/10.21037/jgo.2018.03.02

11. Shapiro JA, Soman AV, Berkowitz Z, Fedewa SA, Sabatino SA, de Moor JS, Clarke TC, Doria-Rose VP, Breslau ES, Jemal A, Nadel MR (2021) Screening for Colorectal Cancer in the United States: Correlates and Time Trends by Type of Test. Cancer epidemiology, biomarkers \& prevention: a publication of the American Association for Cancer Research. cosponsored by the American Society of Preventive Oncology 30(8):1554-1565. https://doi.org/10.1158/1055-9965.EPI-20-1809

12. Kasting ML, Haggstrom DA, Lee JL, Dickinson SL, Shields CG, Rawl SM (2021) Financial hardship is associated with lower uptake of colorectal, breast, and cervical cancer screenings. Cancer causes control: CCC. 10.1007/s10552-021-01465-7. Advance online publication. https://doi.org/10.1007/s10552-021-01465-7

13. Coverage of Colonoscopies Under the Affordable Care Act's prevention benefit, Kaiser Family Foundation, American Cancer Society, and National Colorectal Cancer Roundtable (2012)

14. Carethers JM (2021) Racial and ethnic disparities in colorectal cancer incidence and mortality. Adv Cancer Res 151:197-229. https://doi.org/10.1016/bs.acr.2021.02.007

15. de Moor JS, Cohen RA, Shapiro JA, Nadel MR, Sabatino SA, Yabroff R, Fedewa K, Lee S, Doria-Rose RPaul, Altice V, C., \& Klabunde CN (2018) Colorectal cancer screening in the United States: Trends from 2008 to 2015 and variation by health insurance coverage. Preventive medicine 112:199-206. https://doi.org/10.1016/j.ypmed.2018.05.001

16. Centers for Disease Control and Prevention (2021, May 03) National Health Interview Survey (NHIS). US Department of Health and Human Services, Centers for Disease Control and Prevention. http://www.cdc.gov/nchs/nhis.htm

17. Bai Y, Wong CL, He X, Wang C, So W (2020) Effectiveness of tailored communication intervention in increasing colonoscopy screening rates amongst first-degree relatives of individuals with colorectal 
cancer: A systematic review and meta-analysis. International journal of nursing studies 101:103397. https://doi.org/10.1016/j.ijnurstu.2019.103397

18. Tan KK, Lim TZ, Chew E, Chow WM, Koh GC (2020) Colorectal cancer patients can be advocates for colorectal cancer screening for their siblings: A study on siblings' perspectives. Psycho-oncology, 29(12), 2028-2032. https://doi.org/10.1002/pon.5496 +

19. Kasting ML, Haggstrom DA, Lee JL, Dickinson SL, Shields CG, Rawl SM (2021) Financial hardship is associated with lower uptake of colorectal, breast, and cervical cancer screenings. Cancer causes control: CCC. 10.1007/s10552-021-01465-7. Advance online publication. https://doi.org/10.1007/s10552-021-01465-7

20. Witte J, Mehlis K, Surmann B et al (2019) Methods for measuring financial toxicity after cancer diagnosis and treatment: a systematic review and its implications. Ann Oncol 30(7):1061-1070. https://doi:10.1093/annonc/mdz140

21. Altice CK, Banegas MP, Tucker-Seeley RD, Yabroff KR (2016) Financial Hardships Experienced by Cancer Survivors: A Systematic Review. J Natl Cancer Inst 109(2):djw205. doi:10.1093/jnci/djw205

22. American Cancer Society (2021) Insurance Coverage for Colorectal Cancer Screening. https://www.cancer.org/cancer/colon-rectal-cancer/detection-diagnosis-staging/screening-coveragelaws.html

23. Lagerlund $M$, Åkesson $A$, Zackrisson S (2021) Change in mammography screening attendance after removing the out-of-pocket fee: a population-based study in Sweden (2014-2018). Cancer causes \& control: CCC, 10.1007/s10552-021-01476-4. Advance online publication. https://doi.org/10.1007/s10552-021-01476-4

24. Laiyemo AO, Thompson N, Williams CD, Idowu KA, Bull-Henry K, Sherif ZA, Lee EL, Brim H, Ashktorab $\mathrm{H}$, Platz EA, Smoot DT (2015) Race and colorectal cancer screening compliance among persons with a family history of cancer. World journal of gastrointestinal endoscopy 7(18):1300-1305. https://doi.org/10.4253/wjge.v7.i18.1300

25. Sly JR, Edwards T, Shelton RC, Jandorf L (2013) Identifying barriers to colonoscopy screening for nonadherent African American participants in a patient navigation intervention. Health education behavior: the official publication of the Society for Public Health Education 40(4):449-457. https://doi.org/10.1177/1090198112459514

26. Ponce NA, Tsui J, Knight SJ, Afable-Munsuz A, Ladabaum U, Hiatt RA, Haas JS (2012) Disparities in cancer screening in individuals with a family history of breast or colorectal cancer. Cancer 118(6):1656-1663. https://doi.org/10.1002/cncr.26480

27. Valery JR, Applewhite A, Manaois A, Dimuna J, Sher T, Heckman MG, Brushaber DE, Stancampiano F (2020) A Retrospective Analysis of Gender-Based Difference in Adherence to Initial Colon Cancer Screening Recommendations. Journal of primary care community health 11:2150132720931321. https://doi.org/10.1177/2150132720931321 